\title{
ЗАСТОСУВАННЯ ЗАВДАННЯ ВИБОРУ В ОНТОГРАФАХ ДЛЯ ДОСЛІДЖЕННЯ ТА АНАЛІЗУ СТАНУ ЗДОРОВ'Я УЧНІВ НА ОСНОВІ РЕЗУЛЬТАТІВ МЕДИЧНОЇ ДІАГНОСТИКИ
}

В. В. Горборуков

\author{
Національний університет «Києво-Могилянська академія»
}

\section{APPLICATION FOR THE PROBLEM OF ONTOHRAPH CHOICE FOR RESEARCH AND ANALYSIS OF THE STUDENTS HEALTH THAT BASED ON MEDICAL DIAGNOSIS}

\section{National University of "Kyiv-Mohyla Academy»}

\author{
V. V. Horborukov
}

Вступ. Онтологія деякого операційного середовища в загальному випадку формально представляється впорядкованою трійкою:

$O=<X, R, F>$,

де $X, R, F$ - кінцеві множини відповідно:

$X$ - концептів (понять, термінів) предметної області (ПрО), на основі яких формується предметна складова операційного середовища;

$R$ - відношень та властивостей між ними (будемо вважати, що властивості є інтерпретацією відношень, тобто існує перетворення, яке кожному відношенню встановлює відповідність певної властивості);

$F$ - функцій інтерпретації (визначень) $X$ та/ або $R$, що складають функціональну частину операційного середовища.

Будь яка онтологія може бути представлена у вигляді певного графу, вершини якого утворюються 3 об'єктів множини концептів, а ребра - 3 бінарних відношень, які задаються між ними при формуванні онтологічної системи. Якщо онтологічна система утворює графи без циклів, то отримуємо онтологічний граф (онтограф), що забезпечує відображення певної ієрархічної структури на множині концептів.

Результати та їх обговорення. Онтографи є потужним інструментарієм для збереження та структуризації інформації (даних) певних ПрО, гнучкість яких значно перевищує можливості традиційних баз даних, що представляються у вигляді реляційних таблиць. На практиці часто виникає потреба у розв'язку задачі ранжування (вибору), що є класичною задачею теорії прийняття рішень. Математично такі задачі описуються набором альтернатив $x \in A=\left\{A_{1}, \ldots, A_{n}\right\}$, для кожної з яких задаються значення $m$ певних показників (критеріїв). Розв'язком такої задачі вважається альтернатива, яка має найкращі (за сукупністю) значення критеріїв, які на практиці, як правило, відрізняються різною важливістю (ваговими коефіцієнтами).

Для формування множини альтернатив та критеріїв із певного онтографу необхідно задати деяку множину обмежень $R s: R s \subset R$, що визначають властивості концептів ПрО і можуть трактуватися як критерії, які визначають область дії поняттєвих структур (концепти, поняття, висловлювання, твердження) визначеної тематики. Також $R s$ дозволяє виділити 3 множини концептів $X$ підмножину альтернатив $A$ за певними правилами.

У загальному випадку критерієм можна вважати деяку функцію $(f)_{j}(x), j \in J=\{1 \ldots m\}$, визначену на множині альтернатив. Зิначення цієї функції належать або до наперед визначеної множини, або обраховуються у відповідності 3 певними математичними правилами. У першому випадку можливі варіанти: множина значень задається бальною чи лінгвістичною шкалою або у вигляді числового інтервалу $\left[f_{j}^{\text {min }}, f_{j}^{\text {max }}\right]$ який утворюється з усіх можливих значень функції (з мінімального до максимального) з урахуванням точності їі обчислення. Прикладом другого випадку є синтез 
локальних пріоритетів у методі аналізу ієрархій. Отже, можна вважати, що значення ј-го критерію завжди є зліченною множиною, позначимо iï як $Q_{j^{\prime}}$ Найкращим вважають результат, що відповідає максимальному або мінімальному значенню функції $f_{j}(x), j \in J$ залежно від напряму оптимізації критерію. Нехай $J_{1}$ і $J_{2}$ - множини індексів критеріїв, що відповідно максимізуються і мінімізуються $\left(J_{1} \cup J_{2}=J\right)$. Далі будемо вважати, що значення кожної функції $f_{i}(x), j \in J$ належать спільному числовому інтервалу $\left[q_{\min } ; q_{\max }\right] \subset R-$ множини дійсних чисел. У протилежному випадку не важко побудувати відповідне взаємно-однозначне відображення початкових значень $f_{j}(x), j \in J$ утакийінтервал.

Як прийнято у більшості випадків, при розгляді багатокритеріальних задач вводиться вектор $W=\left(w_{1}, \ldots, w_{m}\right)$, кожна компонента якого $w_{j}$ характеризує важливість ј-го критерію, причому $\sum_{j=1}^{m} w_{j}=1, w_{j}>0$.

Задача ранжування альтернатив $x \in A=\left\{A_{1}, \ldots, A_{n}\right\}$ за сукупністю показників $f(x)=\left(f_{1}(x), \ldots, f_{m}(x)\right)$ полягає у встановленні певного порядку

$$
A_{i_{1}}>A_{i_{2}}>\cdots>A_{i_{n}}
$$

на основі обчислення значень деякого узагальненого показника $G(x)$ для кожного елемента множини $X$ :

$$
\begin{aligned}
& G(x)=G(f(x), W)=G\left(\left(f_{1}(x), \ldots, f_{m}(x)\right),\left(w_{1}, \ldots, w_{m}\right)\right), \\
& x \in A=\left\{A_{1}, \ldots, A_{n}\right\}
\end{aligned}
$$

де значення $\mathcal{G}\left(A_{i}\right)$ обчислюються за певним правилом (алгоритмом), що визначається математичним методом, який використовується в кожному конкретному випадку, причому

$$
G\left(A_{i_{1}}\right) \geq G\left(A_{i_{2}}\right) \geq \cdots \geq G\left(A_{i_{n}}\right) .
$$

Так, в теорії прийняття рішень найбільш відомими та поширеними є метод ідеальної точки, лінійно-адитивна згортка, степенево-адитивна згортка та деякі інші.

У задачі ранжування альтернатив найкращою вважають альтернативу $A_{i_{1}}$ яка у порядку (1) займає перше місце, відповідно, найгіршою - альтер нативу $A_{i .}$.

Для розв'язку задачі (1)-(3) створено програмне забезпечення, яке дає особі, що приймає рішення (ОПР), зручний інструментарій для формування задачі вибору на основі даних, присутніх у попередньо створеному онтологічному графі.

Розглянемо результати медичної діагностики за деякими показниками, аналіз яких необхідно провести для виявлення стану здоров'я учнів тестованої групи (рис. 1).

На основі вищенаведених даних будується відповідний онтограф (рис. 2), в якому вершини нижнього рівня ієрархії (учні) розглядаються як альтернативи, а в якості базових критеріїв задачі вибору виступають показники вимірювань (рис. 3).

У випадку, коли за значеннями окремих показників складно робити конкретні висновки, застосовують певні обчислення і отримують інші показники, які вже містять конкретний змістовий фактор (наприклад, «кония. водородных іонів різницяя). Коли множина критеріїв сформована i встановлені для них вагові коефіцієнти, можливе

\begin{tabular}{|c|c|c|c|c|c|c|c|c|c|c|c|c|c|c|c|c|}
\hline 4 & A & B & c & D & E & $\mathrm{F}$ & G & H & 1 & J & K & L & M & $\mathrm{N}$ & 0 & P \\
\hline 1 & $\begin{array}{l}\text { № } \\
\text { п/П }\end{array}$ & ID & Ф.и.о. & Пол & Возраст & Дата & $\begin{array}{l}\text { Время } \\
\text { дня }\end{array}$ & $\begin{array}{l}\text { Конц.вод } \\
\text { ородных } \\
\text { ионов } \\
\text { Без ноз }\end{array}$ & $\begin{array}{l}\text { Конц.вод } \\
\text { ородных } \\
\text { ионов } \\
\text { С нозод }\end{array}$ & \begin{tabular}{|l|} 
Конц.вод \\
ородных \\
ионов \\
Разница
\end{tabular} & \begin{tabular}{|l|} 
Повыше \\
нная \\
восприи \\
мчивость \\
Без ноз
\end{tabular} & \begin{tabular}{|l|} 
Повыше \\
нная \\
восприи \\
мчивость \\
С нозод
\end{tabular} & \begin{tabular}{|l|} 
Повыше \\
нная \\
восприи \\
мчивость \\
Разниці_
\end{tabular} & $\mid \begin{array}{l}\text { Средняя } \\
\text { восприи } \\
\text { мчивость } \\
\text { Без ноз }\end{array}$ & $\begin{array}{l}\text { Средняя } \\
\text { восприи } \\
\text { мчивость } \\
\text { С нозод }\end{array}$ & $\begin{array}{l}\text { Средняя } \\
\text { восприи } \\
\text { мчивость } \\
\text { Разница }\end{array}$ \\
\hline 2 & 1 & 1 & Аллахмердиев Тура И. & $M$ & 15 & 20.11 .2013 & утро & 41 & 44 & 3 & 37 & 34 & -3 & 37 & 41 & 4 \\
\hline 3 & 2 & 2 & Багмет K. & ж & 15 & 20.11 .2013 & утро & 31 & 28 & -3 & 26 & 29 & 3 & 28 & 29 & 1 \\
\hline 4 & 3 & 3 & Беседин 3.В. & M & 15 & 20.11 .2013 & утро & 51 & 45 & -6 & 37 & 46 & 9 & 33 & 33 & 0 \\
\hline 5 & 4 & 4 & Бескаравайная Ольга Юр & ж & 15 & 20.11 .2013 & утро & 27 & 30 & 3 & 20 & 23 & 3 & 22 & 26 & 4 \\
\hline 6 & 5 & 5 & Водолазская Н.А. & ж & 15 & 20.11 .2013 & утро & 33 & 33 & 0 & 20 & 26 & 6 & 19 & 23 & 4 \\
\hline 7 & 6 & 6 & Водопьянов Артем & $M$ & 15 & 20.11 .2013 & утро & 40 & 40 & 0 & 42 & 40 & -2 & 43 & 51 & 8 \\
\hline 8 & 7 & 7 & Долгих К.И. & $M$ & 16 & 20.11 .2013 & утро & 30 & 25 & -5 & 20 & 42 & 22 & 23 & 26 & 3 \\
\hline 9 & 8 & 8 & Зеленов Д.В. & $M$ & 15 & 20.11 .2013 & утро & 37 & 38 & 1 & 25 & 38 & 13 & 22 & 27 & 5 \\
\hline 10 & 9 & 9 & Казаринова К. & ж & 15 & 20.11 .2013 & утро & 29 & 28 & -1 & 31 & 30 & -1 & 32 & 41 & 9 \\
\hline 11 & 10 & 10 & Кормилец А.О. & ж & 15 & 20.11 .2013 & утро & 30 & 35 & 5 & 41 & 42 & 1 & 44 & 55 & 11 \\
\hline 12 & 11 & 11 & Лобачева К.И. & ж & 16 & 20.11 .2013 & утро & 42 & 42 & 0 & 29 & 34 & 7 & 29 & 29 & 0 \\
\hline 13 & 12 & 12 & Мирошничеенко Д.Д. & $M$ & 15 & 20.11 .2013 & утро & 34 & 38 & 4 & 28 & 30 & 2 & 29 & 46 & 17 \\
\hline 14 & 13 & 13 & Мостовой Александр Д. & $M$ & 15 & 20.11 .2013 & утро & 50 & 54 & 4 & 36 & 35 & -1 & 34 & 35 & 1 \\
\hline 15 & 14 & 14 & Мостовой Алексей Д. & $M$ & 16 & 20.11 .2013 & утро & 28 & 41 & 13 & 43 & 42 & -1 & 38 & 40 & 2 \\
\hline
\end{tabular}
розв'язання задачі ранжування, де результатом буде певний рейтинговий список стану пацієнтів (від кращзого до гіршого) (рис. 4) .

Puc 1. Фрагмент таблиці результатів медичної діагностики учнів. 


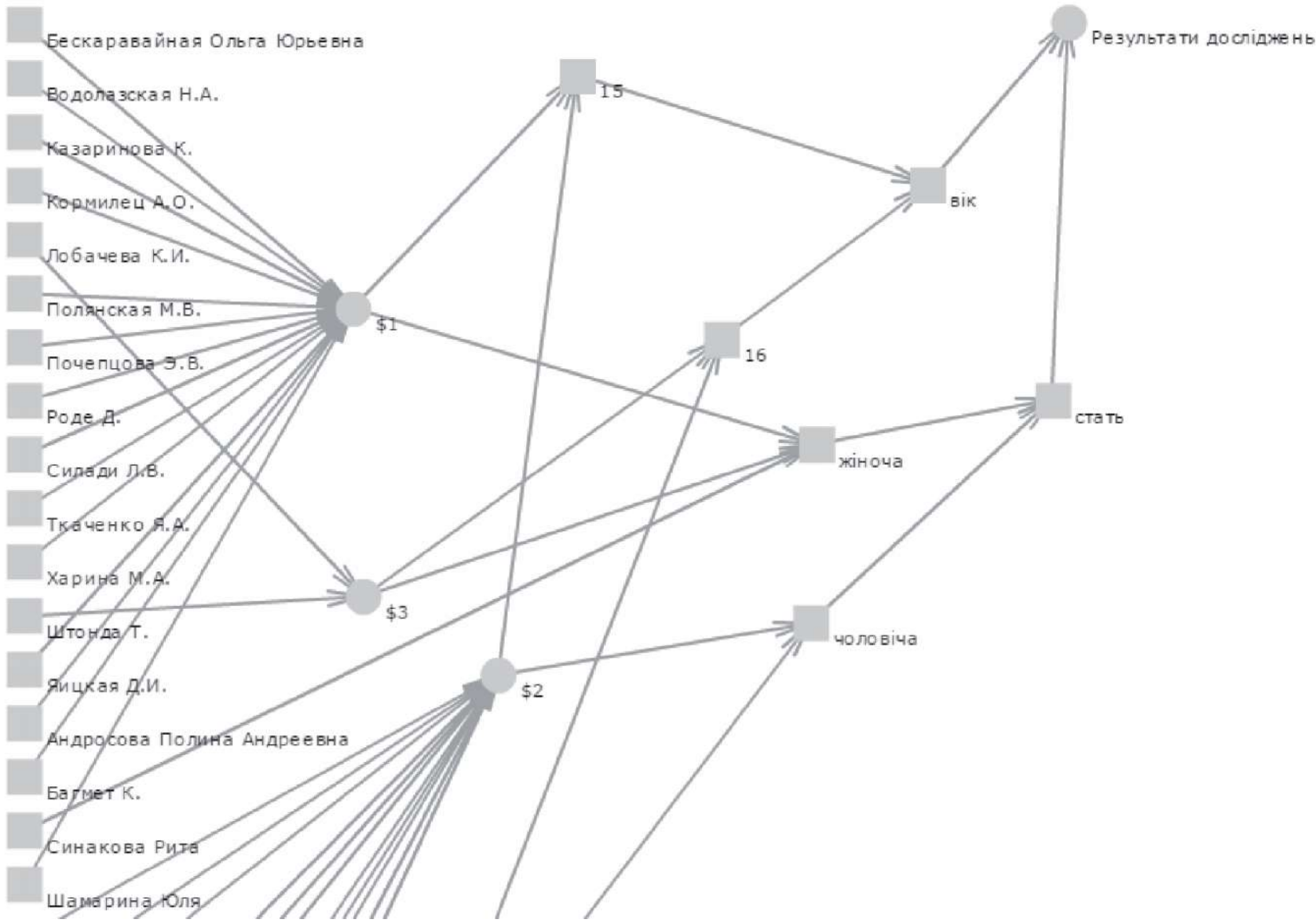

Puc. 2. Фрагмент онтографа, створеного на основі даних медичної діагностики.

Враховуються властивості

Опрацювати

\begin{tabular}{|c|c|c|c|c|c|c|}
\hline \multirow{2}{*}{ Вибір } & \multirow{2}{*}{ Ім'я } & \multirow{2}{*}{$\begin{array}{l}\text { Bar. } \\
\text { Koeq. }\end{array}$} & \multirow{2}{*}{$\begin{array}{c}\text { Oпт } \\
\text { (maximin) }\end{array}$} & \multicolumn{3}{|c|}{ Способи задання вагових коефіцієнтів } \\
\hline & & & & Бальна шкала (10) & Лінгвістична шкала & Ранжування \\
\hline 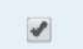 & Конц, водородных ионов Без ноз & 0.032 & $\max \times$ & $5 \cdot$ & Середня важливість • & $1 \cdot$ \\
\hline$\downarrow$ & Конц.водородных ионов с нозод & 0.032 & $\max \cdot$ & $5 \cdot$ & Середня важливість - & $1 \cdot$ \\
\hline$\checkmark$ & Конц.водородных ионов Разница & 0.032 & $\max \cdot$ & $5 \cdot$ & Середня важливість - & $1 \cdot$ \\
\hline$\downarrow$ & Повышенная восприимчивость без ноз & 0.032 & $\max \cdot$ & 5 . & Середна важливість - & 1 , \\
\hline$\checkmark$ & Повышенная восприимчивость С нозод & 0.032 & $\max \cdot$ & $5 \cdot$ & Середня важливість ' & 1 \\
\hline$\checkmark$ & Повышенная восприимчивость Разница & 0.032 & $\max \cdot$ & 5 . & Середня важливість ' & 1 . \\
\hline$\checkmark$ & Средняя восприимчивость Без ноз & 0.032 & $\max \cdot$ & $5 \cdot$ & Середня важливість - & $1 \cdot$ \\
\hline$\downarrow$ & Средняя восприимчивость С нозод & 0.032 & $\max \cdot$ & $5 \cdot$ & Середня важливість - & $1 \cdot$ \\
\hline$\checkmark$ & Средняя восприимчивость Разница & 0.032 & $\max *$ & 5. & Середня важливість , & $1 \cdot$ \\
\hline
\end{tabular}

Puc. 3. Фрагмент критеріальної таблиці. 


\begin{tabular}{|c|c|c|c|c|c|c|c|c|}
\hline \# & Елементи & Значення & $\begin{array}{l}\text { Конц.водородных } \\
\text { ионов Без ноз }\end{array}$ & $\begin{array}{l}\text { Конц.водородных } \\
\text { ионов с созод }\end{array}$ & $\begin{array}{l}\text { Конц. водородных } \\
\text { ионов Разница }\end{array}$ & $\begin{array}{c}\text { Повышенная } \\
\text { восприимчивость } \\
\text { без ноз }\end{array}$ & $\begin{array}{c}\text { Повышенная } \\
\text { восприимчивость } \\
\text { С нозод }\end{array}$ & $\begin{array}{c}\text { Повышенная } \\
\text { восприимчивость } \\
\text { Разница }\end{array}$ \\
\hline 1 & Смелянский с. & 0.797 & 44 & 51 & 7 & 49 & 55 & 6 \\
\hline 2 & Павлусенко В.и. & 0.758 & 35 & 42 & 7 & 52 & 54 & 2 \\
\hline 3 & Захарьян А. & 0.753 & 33 & 38 & 5 & 34 & 66 & 32 \\
\hline 4 & $\begin{array}{c}\text { Алпахмердиев } \\
\text { Тура и. }\end{array}$ & 0.743 & 25 & 43 & 18 & 43 & 43 & 0 \\
\hline 5 & $\begin{array}{l}\text { Водопьянов } \\
\text { Артем }\end{array}$ & 0.742 & 41 & 43 & 2 & 42 & 48 & 6 \\
\hline 6 & $\begin{array}{c}\text { Андросова } \\
\text { Полина } \\
\text { Андрееннна }\end{array}$ & 0.733 & 25 & 43 & 18 & 43 & 43 & 0 \\
\hline
\end{tabular}

Puc. 4. Фрагмент рейтингового списку.

Для змістовного дослідження проблеми ОПР може виключати з розгляду ті чи інші показники, знімаючи відповідні відмітки у стовпчику з заголовком «Вибір», та корегуючи значення важливостей цих показників.

Зауважимо, що у ОПР є можливість штучно створювати альтернативи. Значення критеріїв для них ОПР може задавати власноруч, для проведення аналітичних досліджень. Такі альтернативи зазвичай будуються на основі вже існуючих. Далі на основі отриманого розв'язку задачі (рейтинговий список альтернатив) з'являється можливість виявити найбільш критичні показники, що дозволить у підсумку виявити та виробити дієвий механізм впливу на проблему.
Висновки. Введення до розгляду штучно створених альтернатив додатково дає можливість більш повного дослідження проблемної задачі. Тут мається на увазі підхід, пов'язаний 3 формуванням так званих «еталонних» альтернатив. Ці альтернативи реально на практиці чи в природі не існують, проте надаючи їм «ідеальні» значення критеріїв, ОПР може провести достатньо грунтовний аналіз, порівнюючи ці альтернативи 3 існуючими.

Для успішного використання розробленого програмного забезпечення необхідно володіти навичками користувача комп'ютера та бути фахівцем тієї предметної галузі, в якій розглядається та чи інша задача багатокритеріального ранжування альтернатив. 